\title{
Alemtuzumab-associated diffuse alveolar damage - a case report
}

\author{
Antonios Bayas ${ }^{1 *}$ (D), Martina Menacher ${ }^{1}$, Martin Schwaiblmair ${ }^{2}$, Bruno Märkl ${ }^{3}$ and Markus Naumann ${ }^{1}$
}

\begin{abstract}
Background: Identifying causes of alemtuzumab induced respiratory symptoms in Multiple Sclerosis (MS) patients is crucial.

Case presentation: We report a case of diffuse alveolar damage (DAD) in a patient with MS after the first course of alemtuzumab treatment. A 42-year-old female developed progressive non-productive cough and exertional dyspnea 2 months after alemtuzumab treatment. DAD was diagnosed histopathologically by lung biopsy. The patient recovered completely, alemtuzumab was not continued.

Conclusions: Our case highlights another pathomechanism for non-infective lung-disorders in alemtuzumab treated MS patients. DAD is a potential, albeit rare side effect of alemtuzumab, broadening the spectrum of noninfective lung disorders that should be considered in the diagnostic work-up.
\end{abstract}

Keywords: Multiple sclerosis, Alemtuzumab, Diffuse alveolar damage, Case report

\section{Background}

Alemtuzumab is a humanized monoclonal antibody, which targets the surface molecule CD52 on immune cells ( $\mathrm{T}$ - and B-cells, monocytes, dendritic cells and thymocytes) and leads to a rapid and significant depletion of those cell types [1]. Well-known side effects include an increased infection rate including respiratory tract infections and secondary autoimmune reactions mainly consisting of thyroid disorders, immune thrombocytopenia, anti-glomerular basement membrane (GBM) disease and membranous glomerulonephritis, which may occur after years of first treatment. Since its approval by the European Medicines Agency (EMA) in 2013, non-infective respiratory tract side effects causing dyspnea have been reported in patients treated with alemtuzumab including diffuse alveolar hemorrhage [2], pneumonitis [3], anti-GBM antibody disease [4] and acute

\footnotetext{
* Correspondence: antonios.bayas@uk-augsburg.de

${ }^{1}$ Neurology and Clinical Neurophysiology, University Hospital of Augsburg, Stenglinstrasse 2, 86156 Augsburg, Germany

Full list of author information is available at the end of the article
}

respiratory distress syndrome (ARDS) [5]. Five cases of diffuse alveolar damage (DAD) associated with alemtuzumab have been reported to VigiBase $\odot$, the World Health Organization's international database for suspected adverse drug reactions [6], without providing further details on treated disorders or other potentially confounding factors. Our report describes a patient with DAD after alemtuzumab treatment for MS. Compared to cases of alemtuzumab associated DAD published so far [6], here we present detailed clinical data and results of apparative diagnostics, furthermore histological findings that have so far not been reported in ARDS associated with alemtuzumab treatment [5].

\section{Case presentation}

A 42-year-old, non-smoking female with highly active relapsing remitting multiple sclerosis (MS) and no concomitant diseases was first diagnosed in 2008. Interferon beta (IFNB)-1a intramuscularly, injected 03/2008, was stopped due to a suspected allergic reaction, intradermal testing for IFNB-1a and $-1 \mathrm{~b}$ could not exclude an 
allergic reaction. Glatiramer acetate had to be withdrawn after 4 months $(07 / 2008-11 / 2008)$ for elevated liver enzymes. Due to high disease activity natalizumab was initiated in 2009 and stopped in 2012 because of JC-virus antibody positivity, hereafter the patient refused further immunotherapies. After a severe relapse resolving only after plasma exchange (PLEX), treatment with fingolimod was initiated, but stopped after 4 months due to another severe relapse requiring treatment with glucocorticosteroids and again PLEX. After 2 further relapses and magnetic resonance imaging (MRI) activity in 2013, treatment with alemtuzumab was decided.

In January 2014 alemtuzumab (12 mg daily) was applied over 5 days, methylprednisolone $1 \mathrm{~g}$, dimetindene, ranitidine, acyclovir and ibuprofen were given as concomitant medication. Except of fatigue and a mild bradycardia, infusions were well-tolerated. After 2 months, progressive non-productive cough, exertional dyspnea and general exhaustion developed. Creactive protein and leucocytes were normal. Computed tomography- (CT-) scan of the lung showed atelectasis in both lower lobes without evidence of atypical pneumonia. Lung function tests showed a high-grade restriction in diffusion capacity (diffusing capacity of the lung for carbon monoxide $\left(\mathrm{D}_{\mathrm{LCO}}\right) 45 \%$ of normal) as well as a respiratory alkalosis ( $\mathrm{pH} 7.46$, $\mathrm{pCO}_{2} 34.3 \mathrm{mmHg}$ ), a respiratory partial insufficiency in ergospirometry (decrease of $\mathrm{pO}_{2}$ from $89 \mathrm{mmHg}$ to $78 \mathrm{mmHg}$ and increase of lactate from 1.0 to 5.5 $\mathrm{mmol} / \mathrm{l}$ during exercise with $150 \mathrm{watt})$ and a lowgrade restrictive lung disease (vital capacity (VC): $2.75 \mathrm{l}$, reference: $\geq 3.70 \mathrm{l}$ ) without obstructive impairment $\left(\mathrm{FEV}_{1}\right.$ (forced expiratory volume in $\left.1 \mathrm{~s}\right) / \mathrm{VC}$ : $88.7 \%$, reference: $\geq 80.9 \%$ ). Bronchoalveolar lavage revealed a moderately active inflammation and a reduced $C D 4 / C D 8$-ratio $(0,67$; reference $\approx 2)$ consistent with an extrinsic allergic alveolitis or a damage of pneumocytes due to drug toxicity. However, an extrinsic allergic alveolitis seemed unlikely because of negative specific IgG antibodies. The Prick test and Methacholin provocation test, suggesting an allergic reaction or a hyperreagibility of the bronchial system, were negative. Histopathologically, hyperplasia of alveolar pneumocytes and remnants of hyaline membranes consistent with a diffuse alveolar damage were found in a transbronchial lung biopsy (Fig. 1). There was no evidence for an infectious agent. Renal function, urine test and anti-GBM antibodies indicating an alemtuzumab-associated Goodpasture syndrome, were unremarkable. Platelets and thyroid function were normal, thyroid antibodies were not determined.

Based on these results, a diffuse alveolar damage (DAD) related to alemtuzumab drug toxicity was

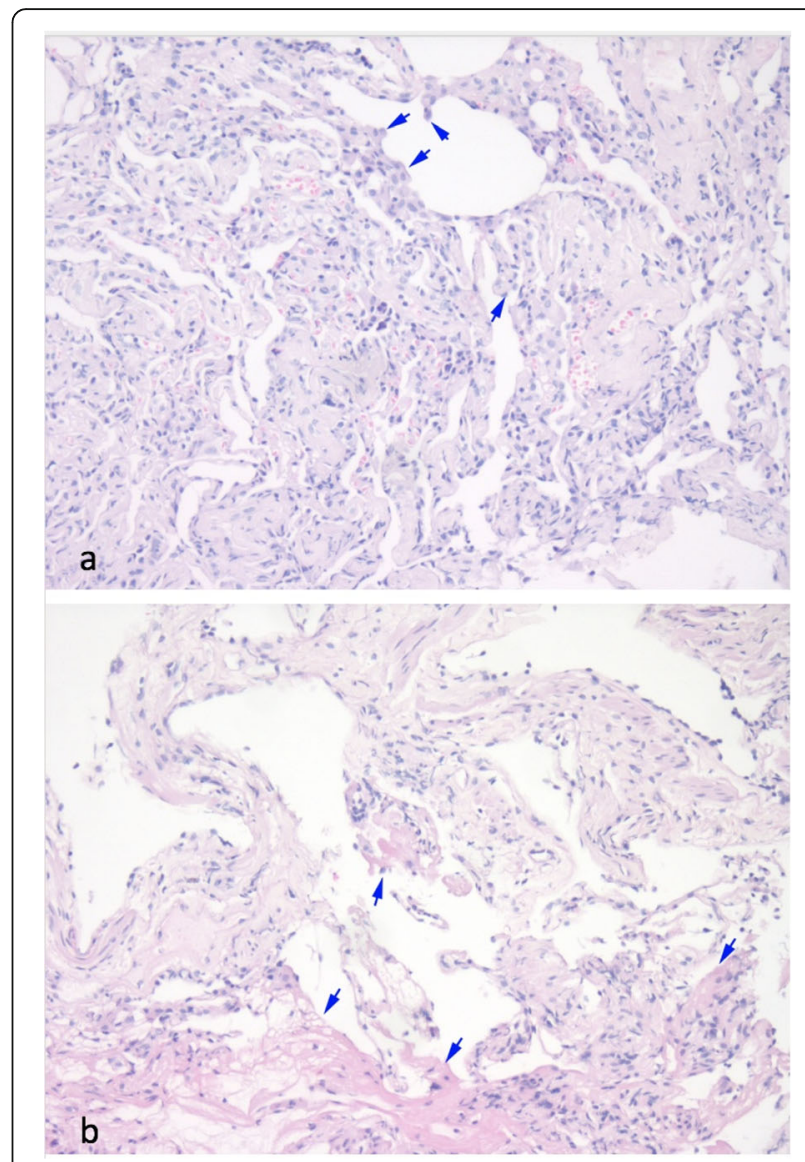

Fig. 1 Lung biopsy, hematoxylin and eosin stain: a arrows indicate activated pneumocytes, $\mathbf{b}$ arrows indicate residual hyaline membranes

diagnosed. Respiratory symptoms regressed over few months, no corticosteroids were given. Diffusion capacity in December 2014 and December 2015 had constantly improved (single-breath-methode, $\mathrm{D}_{\mathrm{LCO}} 71,5$ and $81 \%$ respectively of normal). Blood gas analysis and lung function tests were normal lately.

Due to the increased risk for recurrent toxicity, alemtuzumab was not continued and treatment switched to rituximab (off-label) in January 2015. MS clinical course and MRI controls have been stable since 2014. The disease course and treatments are shown in Fig. 2. Written informed consent for patient information and images to be published was provided by the patient.

\section{Discussion and conclusions}

Over the last years, reports of serious adverse events also affecting the lungs have prompted the EMA to amend the label for alemtuzumab [7]. More recently, further cases of treatment-induced lung injury have broadened the spectrum of non-infective respiratory disorders after alemtuzumab treatment in MS [5]. To our knowledge, 


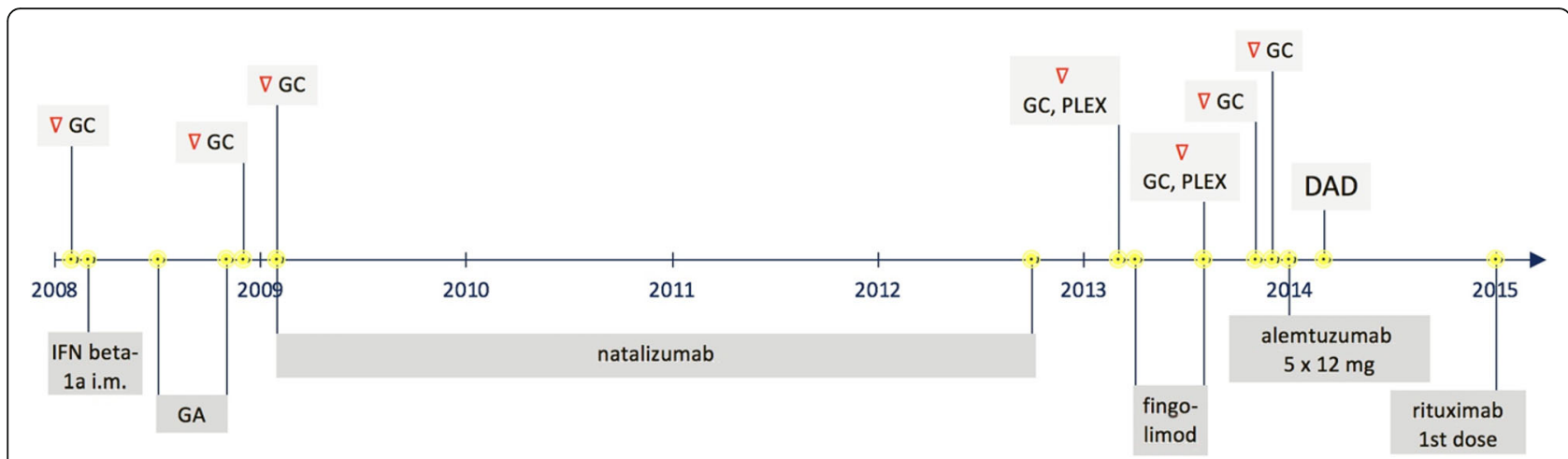

Fig. 2 Disease course and applied treatments. IFN = interferon; GA = glatiramer acetate; $\nabla=$ relapse; $G C=$ glucocorticosteroids; PLEX = plasma exchange; $\mathrm{DAD}$ = diffuse alveolar damage

our case is the first report of DAD in MS after alemtuzumab treatment examined histologically. ARDS as a clinical correlate of DAD after alemtuzumab treatment in MS has recently been published, but lung biopsy is not reported [5]. DAD is characterized by dyspnea and dry cough progressing over a period of days or weeks. High-resolution CT typically shows a combination of ground-glass opacity and consolidation involving predominantly dependent regions or distributed more randomly throughout both lungs [8]. DAD can be induced by infections, inhalational injuries, connective tissue diseases and also drugs [9]. It is the most commonly reported histologic manifestation of drug toxicity usually developing after a few weeks or months [8]. The mortality rate in DAD has been reported to be high. In a series of 58 patients with DAD diagnosed by surgical lung biopsy over a 7-year period, $60 \%$ were immunocompromised. In this study, the most common cause of DAD were infections (22\%), drugs were found to be causal in $10 \%$ of cases. The overall hospital mortality rate associated with DAD was $53 \%$, in the group of drug induced DAD 1 of 6 patients died [9]. In our case, respiratory symptoms occurred 2 months after the alemtuzumab cycle, according to the latency known from other drugs. Fortunately, the patient reported gradually recovered over months without subjective residual symptoms. Apart from atelectasis, the initial CT scan revealed no abnormal findings indicating a milder lung involvement and possibly explaining a less severe disease course.

Various pathological phenomena underlying DAD have been reported, among them endothelial and alveolar cell injury leading to fluid and cellular exsudation with hyaline membranes and edema [10]. The mechanism underlying alemtuzumab induced DAD is unknown. In diffuse alveolar hemorrhage after alemtuzumab treatment, it has been speculated that alemtuzumab induced effector mechanisms lead to acute inflammation that may damage membranes and cells not expressing CD52 [2].

Our report shows that DAD is a potential, albeit rare side effect of alemtuzumab, broadening the spectrum of non-infective lung disorders that should be considered in the diagnostic work-up.

\section{Abbreviations}

MS: Multiple sclerosis; DAD: Diffuse alveolar damage; GBM: Anti-glomerular basement membrane; EMA: European Medicines Agency; ARDS: Acute respiratory distress syndrome; IFNB: Interferon beta; PLEX: Plasma exchange; MRI: Magnetic Resonance Imaging; CT: Computed tomography; VC: Vital capacity

\section{Acknowledgements}

not applicable.

\section{Authors' contributions}

AB: Acquired and analyzed data and drafted the manuscript. MM: Acquired and analyzed data, revised the manuscript for intellectual content. MS: Acquired and analyzed data, revised the manuscript for intellectual content. BM: Acquired and analyzed data, revised the manuscript for intellectual content. MN: Analyzed data, revised the manuscript for intellectual content. All authors have read and approved the manuscript.

\section{Funding}

Open Access funding enabled and organized by Projekt DEAL.

\section{Availability of data and materials}

All data relevant for the case report have been presented in the manuscript. Further, potentially identifying or confidential patient data will not be shared.

Ethics approval and consent to participate Not applicable.

\section{Consent for publication}

The patient gave written consent for their personal or clinical details along with any identifying images to be published in this study.

\section{Competing interests}

$A B$ has received personal compensation from Merck Serono, Biogen, Novartis, TEVA, Roche, Sanofi/Genzyme and Celgene and grants for congress trips and participation from Biogen, TEVA, Novartis, Sanofi/Genzyme, Merck Serono and Celgene.

MM: none. MS has received personal compensation from Actelion, AstraZeneca, Bayer, Berlin-Chemie, Boehringer-Ingelheim, Chiesi, GlaxoSmithKline, Janssen-Cilag, MSD, Novartis und Roche. BM: none. MN: none. 


\section{Author details}

'Neurology and Clinical Neurophysiology, University Hospital of Augsburg, Stenglinstrasse 2, 86156 Augsburg, Germany. ${ }^{2}$ Internal Medicine I-Cardiology, University Hospital of Augsburg, Stenglinstrasse 2, 86156 Augsburg,

Germany. ${ }^{3}$ General Pathology and Molecular Diagnostics, Medical Faculty,

University of Augsburg, Stenglinstrasse 2, 86156 Augsburg, Germany.

Received: 11 July 2020 Accepted: 15 September 2020

Published online: 23 September 2020

\section{References}

1. Havrdova E, Horakova D, Kovarova I. Alemtuzumab in the treatment of multiple sclerosis: key clinical trial results and considerations for use. Ther Adv Neurol Disord. 2015;8:31-45. https://doi.org/10.1177/ 1756285614563522.

2. Myro AZ, Bjerke G, Zarnovicky S, et al. Diffuse alveolar hemorrhage during alemtuzumab infusion in a patient with multiple sclerosis: a case report. BMC Pharmacol Toxicol. 2018;19:75. 2018/11/21. https://doi.org/10.1186/ s40360-018-0267-5.

3. Whiteside $D$, Barth $S$, Datta $A$, et al. Pneumonitis secondary to alemtuzumab in a patient with multiple sclerosis - A non-infectious cause of breathlessness. Mult Scler Relat Disord. 2018;22:139-40. 2018/04/24. https:// doi.org/10.1016/j.msard.2018.04.002.

4. https://pneumotox.com. accessed on april 26th, 2020.

5. Bianco A, Mari PV, Larici AR, et al. Alemtuzumab-induced lung injury in multiple sclerosis: Learning from adversity in three patients. Mult Scler Relat Disord. 2020;37:101450. 2019/11/02. https://doi.org/10.1016/j.msard.2019. 101450.

6. Uppsala Monitoring Centre. VigiBase tWHO and reactions. idosad. https:// www.who-umc.org/vigibase/vigibase/accessed April, 26th, 2020.

7. Hartung HP, Mares J, Barnett MH. Alemtuzumab: Rare serious adverse events of a high-efficacy drug. Mult Scler. 2020:1352458520913277. 2020/04/ 17. https://doi.org/10.1177/1352458520913277.

8. Myers JL, Limper AH, Swensen SJ. Drug-induced lung disease: a pragmatic classification incorporating HRCT appearances. Semin Respir Crit Care Med. 2003;24:445-54. 2005/08/10. https://doi.org/10.1055/s-2003-42379.

9. Parambil JG, Myers $J$, Aubry MC, et al. Causes and prognosis of diffuse alveolar damage diagnosed on surgical lung biopsy. Chest. 2007;132:50-7. 2007/05/04. https://doi.org/10.1378/chest.07-0104.

10. Kaarteenaho R, Kinnula VL. Diffuse alveolar damage: a common phenomenon in progressive interstitial lung disorders. Pulm Med. 2011; 2011:531302. 2011/06/04. https://doi.org/10.1155/2011/531302.

\section{Publisher's Note}

Springer Nature remains neutral with regard to jurisdictional claims in published maps and institutional affiliations.

Ready to submit your research? Choose BMC and benefit from:

- fast, convenient online submission

- thorough peer review by experienced researchers in your field

- rapid publication on acceptance

- support for research data, including large and complex data types

- gold Open Access which fosters wider collaboration and increased citations

- maximum visibility for your research: over $100 \mathrm{M}$ website views per year

At $\mathrm{BMC}$, research is always in progress.

Learn more biomedcentral.com/submissions 